Research Paper

\title{
Human coronavirus ocurrence in different populations of Sao Paulo: A comprehensive nine-year study using a pancoronavirus RT-PCR assay
}

\author{
Tatiane K. Cabeça, Ana Maria Passos, Celso Granato, Nancy Bellei \\ Clinical Virology Laboratory, Department of Medicine, Universidade Federal de São Paulo, \\ São Paulo, SP, Brazil.
}

Submitted: December 20, 2011; Approved: June 7, 2012.

\begin{abstract}
Human coronaviruses ( $\mathrm{HCoVs}$ ) are considered one of the most common respiratory viruses associated with respiratory tract illnesses. An emergent human coronavirus was identified as the causal agent of an epidemic of severe acute respiratory syndrome (SARS) during 2002-2003. The severity of the disease combined with its rapid spread requires the continuous surveillance of coronaviruses in worldwide populations. Epidemiological and clinical data of HCoVs infectious in the Brazilian population are scarce and restricted to one or two groups of patients. Our study aimed to investigate retrospectively the presence of HCoVs in different populations of São Paulo presenting acute respiratory tract infections (ARIs) during the years of 2001-2010. A pancoronavirus RT-PCR was performed in this study. Coronaviruses were detected in $126(11.5 \%)$ of 1,087 specimens. Peaks detection frequency was observed during 2002-2004 and 2008-2009, with the highest detection in 2008. The prevalence of $\mathrm{HCoVs}$ was higher among children with heart diseases $(24.6 \%)$, patients under stem cell transplantation program (24.3\%) and renal transplanted patients (20.2\%). Coryza, cough and fever were the most common symptoms at presentation of positive cases and wheezing, a lower respiratory tract infection symptom was reported by $12 \%$ of the total, and $27 \%$ of high at-risk patients. $\mathrm{HCoVs}$ may have an important role among patients with underlying conditions and transplanted ones.
\end{abstract}

Key words: human coronaviruses, epidemiology, respiratory tract illness, pancoronavirus RT-PCR.

\section{Introduction}

Human coronaviruses (HCoVs) are positivestranded, enveloped RNA viruses classified within the family Coronaviridae (genus, Coronavirus) (Hendley et al., 1972). They are associated mainly with respiratory tract illness but are also involved in enteric and central nervous system diseases (Resta et al., 1985; Murray et al., 1992; Stewart et al., 1992). Until recently only three human coronaviruses were thoroughly studied. Human coronavirus OC43 (HCoV-OC43) and human coronavirus 229E (HCoV-229E) were identified in the 1960s (Hamre and Procknow, 1966) and are well recognized as important pathogens that cause the common cold. A third novel human coronavirus, SARS-CoV, was identified as the causal agent during the 2002-2003 outbreak of severe acute respi- ratory syndrome (SARS) (Drosten et al., 2003). The increase in research on these viruses soon led to discovery of 2 other human coronaviruses, HCoV-NL63 in the Netherlands and HCoV-HKU1 in China (van der Hoek et al., 2004; Woo et al., 2005) both detected in respiratory tract specimens of patients with lower respiratory tract illnesses. Since July 2003 when the last case of SARS associated with the epidemic was reported only four human coronaviruses are known to continuously circulate in the human population. Results from epidemiological studies have led to the conclusion that these viruses are worldwide distributed and circulate with biennial prevalence (McIntosh et al., 1970; Vabret et al., 2003; van Elden et al., 2004; Chiu et al., 2005; Gerna et al., 2007). However, there are few studies that have described the epidemiological and clinical features of human coronaviruses infection among different popula-

Send correspondence to: T.K. Cabeça. Clinical Virology Laboratory, Department of Medicine, Universidade Federal de São Paulo, Rua Pedro de Toledo 781, andar 15, 04039-032 São Paulo, SP, Brazil. E-mail: taticabeca@yahoo.com.br. 
tions, such as at-risk children or adults, patients with underlying conditions, those hospitalized, the immunocompromised patients and others, mainly in South America. In the present study, we retrospectively looked for the presence of $\mathrm{HCoVs}$ in different populations of Sao Paulo presenting acute respiratory tract infections (ARIs) from 2001 to 2010 , to assess the prevalence that $\mathrm{HCoVs}$ infections have on different groups of Brazilian patients and to describe the clinical presentation of the ARIs caused by this virus and their circulation trends in Brazil.

\section{Materials and Methods}

\section{Study design and population}

During the nine-year span studied, respiratory samples were collected from patients presenting acute respiratory illnesses. The study period began in June 2001 and was concluded in September 2010. A total of 1,087 samples were collected. Specimens analyzed included 414 from nasopharyngeal swabs (Labor Swab Import, Brazil), 208 from nasal aspirations and 465 from nasal lavages. Subjects were: 50 adults who were attended by generalpractice physicians among community population patients registered by the Medical Department Outpatient Office during 2001-2003, 86 healthcare workers (HCW) from Sao Paulo Hospital during 2001-2003, 148 renal transplanted patients registered at the Outpatient Office of the Nephrology Division of Sao Paulo Federal University during 2002-2004, 81 children with heart diseases from the pediatric cardiac ambulatory unit of Sao Paulo Federal University during 2005-2008, 329 children outpatients from the general community from the pediatric ambulatory unit of Sao Paulo Federal University during 20082010, 181 patients under stem cell transplantation program registered at the Hematologic Division of São Paulo Hospital during 2008-2009 and 212 hospitalized patients originally suspected of H1N1 2009 infection at Sao Paulo Hospital during 2009-2010.

\section{Inclusion criteria}

Three inclusion criteria were used: patients with a clinical diagnosis of Influenza-Like-Illness (ILI) defined by the presence of fever plus at least one respiratory symptom (cough and/or sore throat) and one constitutional symptom (headache, myalgia, sweat or chills); patients with a clinical diagnosis of Acute Respiratory Infection (ARI) defined by the presence of respiratory symptoms who did not fulfill ILI definition were considered to have ARI; hospitalized patients suspected of 2009 H1N1 Influenza A infection presenting fever $<38{ }^{\circ} \mathrm{C}$, cough and dyspnea. Lower respiratory tract illness was defined as having 1 of the following: supplemental oxygen requirement, mechanical ventilation requirement, or a chest radiograph showing possible or definite infiltrates.

\section{Demographic and clinical data}

Epidemiological and clinical data from outpatients were obtained using a standardized questionnaire while data from hospitalized patients were abstracted from medical charts using a standardized form. Age, gender, occupation, presence of underlying conditions or diseases, clinical findings at first attendance (for outpatients) or during the first 24 hours (for hospitalized patients) were recorded for analysis. Institutional review board approval was received before reviewing any records. This study was approved by the Ethics Committee of Sao Paulo Federal University (CEP 1968/09), and written consent was obtained from all patients or those responsible for the individual patient.

\section{Pancoronavirus RT-PCR one-step assay}

Viral genomic RNA was extracted from the collected specimens by using a QIAamp Viral RNA extraction kit (QIAGEN, Valencia, CA), according to the instructions of the manufacturer. A pancoronavirus RT-PCR assay previously described (Vijgen et al., 2008) with just minor modifications (50 cycles of amplification to 40 and melting temperature from $48{ }^{\circ} \mathrm{C}$ to $50{ }^{\circ} \mathrm{C}$ ), was performed in order to detect human and animal coronaviruses in the samples. The amplification of a $251 \mathrm{bp}$ fragment of the polymerase gene was performed using the following primer set: CorFW (5'-ACWCARHTVAAYYTNAARTAYGC- 3') and Cor-RV (5'-TCRCAYTTDGGRTARTCCCA-3'). These one-step RT-PCR assays (OneStep RT-PCR kit; QIAGEN) were undertaken in a $50 \mu \mathrm{L}$ reaction volume containing $10 \mu \mathrm{L}$ RNA-extract, $10 \mu \mathrm{L}$ 5x QIAGEN OneStep RT-PCR Buffer, $2 \mu \mathrm{L}$ dNTP mix (final concentration of $400 \mu \mathrm{M}$ of each dNTP), 1.8 $\mu$ L QIAGEN OneStep RT-PCR Enzyme Mix (a combination of Omniscript and Sensiscript reverse transcriptase and Hot- StarTaq DNA polymerase), $4 \mu \mathrm{M}$ of each primer, and RNase-free water to $50 \mu \mathrm{L}$. Positive and negative controls were included in each PCR experiment. The reaction was carried out with an initial reverse transcription step at $50{ }^{\circ} \mathrm{C}$ for $30 \mathrm{~min}$, followed by PCR activation at $95{ }^{\circ} \mathrm{C}$ for $15 \mathrm{~min}, 40$ cycles of amplification (30 sec at $94{ }^{\circ} \mathrm{C} ; 30 \mathrm{sec}$ at $50{ }^{\circ} \mathrm{C} ; 1 \mathrm{~min}$ at $72{ }^{\circ} \mathrm{C}$ ), and a final extension step at $72{ }^{\circ} \mathrm{C}$ for $10 \mathrm{~min}$ in a VERITI thermal cycler (Applied Biosystems, Foster City, CA, USA). PCR-products were verified on an agarose gel, stained with ethidium bromide, and visualized under UV-light.

\section{Statistical analysis}

Statistical analysisconsisted of Pearsons chi-square test for the comparison of categorical values, with a significance level of $\mathrm{p}<0.050$.Non-conditional logistic regression was used to identify associations between coronaviruses positivity and the studied populations. All reported values were two-tailed. Results were presented as odds ratio (OR) and therespective $95 \%$ confidence interval (CI) and 
pvalue. All data were entered into and analyzed by using SPSS version 11.0 (SPSS Inc., Chicago, IL, USA).

\section{Results}

Coronaviruses were detected in $126(11.5 \%)$ of 1,087 specimens using the Pancoronavirus RT-PCR assay. Coronaviruses were detected in every month except January with a $20.3 \%$ peak on winter months (July) (Figure 1). Peaks detection frequency was observed during 2002-2004 and 2008-2009, with the highest detection in 2008 (Figure 1). Coronaviruses-positive cases were found from patients ranging in age from 2 months to 80 years, with a median age of 33 years. The majority (59\%) was female. Twenty percent of coronaviruses-infected patients presented underlying diseases other than cardiac and/or transplanted conditions. Fifteen patients had hypertension, 5 had diabetes mellitus, 1 patient was HIV infected and 1 had congenital kidney disease. The prevalence of $\mathrm{HCoV}$ was higher among children with heart diseases $(24.6 \%)$, patients under stem cell transplantation program (24.3\%) and renal transplanted patients $(20.2 \%)$ than others patients groups. Adults from community and healthcare workers showed similar infection rates despite of the occupational risk of the last group. The lowest ratios of coronaviruses- positive cases were obtained in children from community and hospitalized patients, $3.3 \%$ and $1.8 \%$, respectively (Table 1). Coronaviruses-infection was significantly different $(\mathrm{p}<0.05)$ among the studied populations. Children with heart diseases presented the highest risk of acquiring coronavirus infection $(\mathrm{OR}=17.0 ; 95 \%$ CI 5.6 - 51.8; $\mathrm{p} \leq 0.0001$ ) when compared with the other populations by logistic regression analysis.

Coryza, cough and fever were the most common symptoms at presentation, reported in $86 \%, 80 \%$ and $49 \%$ of positive cases, respectively. Clinical characteristics of coronaviruses-infected patients are shown in Table 2. Differences on clinical expressions were obtained among the studied populations $(\mathrm{p}<0.05)$. Fever was less found among both renal and patients under stem cell transplantation program when compared with the other groups. Cyanosis was only reported in 1 child with heart disease and wheezing was reported only among hospitalized patients and children, both from community and with heart diseases. Dyspnea, another lower respiratory tract infection symptom besides wheezing, was documented among patients under stem cell transplantation program, children with heart diseases, children from community and hospitalized patients.

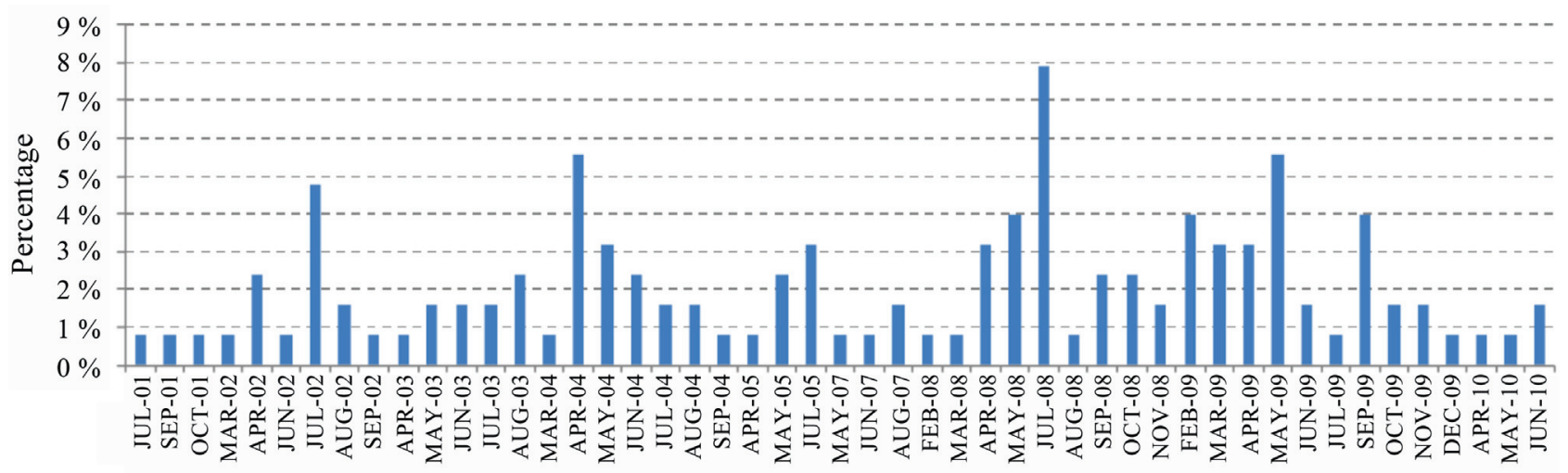

Figure 1 - Coronaviruses detection frequencies by month over the 9 years of the study.

Table 1 - Human coronaviruses infections among Brazilian patients during 9 years of surveillance.

\begin{tabular}{lcccc}
\hline Populations & Tested, no. & Positive specimens & OR & $95 \%$ CI \\
\hline Adults & 50 & $6(12)$ & 7.1 & $3.0-21.0$ \\
HCW & 86 & $11(12.8)$ & 7.6 & $5.7-19.9$ \\
Renal TPL & 148 & $30(20.3)$ & 13.2 & $13.8-26.8$ \\
Children heart dis & 81 & $20(24.7)$ & 17.0 & $15.3-34.1$ \\
SCTP & 181 & $44(24.3)$ & 16.7 & $18.1-30.1$ \\
Comm. children & 329 & $11(3.3)$ & 1.8 & $1.4-5.3$ \\
Hospitalized patients & 212 & $4(1.9)$ & $1($ Ref) & $0.1-3.7$ \\
Total & 1087 & $126(11.6)$ & & $9.7-13.5$ \\
\hline
\end{tabular}

Note. HCW: healthcare workers; renal TPL: renal transplanted patients; children heart dis: children with heart diseases; SCTP: patients under stem cell transplantation program; comm. children: children from community; CI: confidence intervals; OR: odds ratio. 
Table 2 - Clinical data of coronaviruses-infected patients, 2001-2010.

\begin{tabular}{|c|c|c|c|c|c|c|c|}
\hline \multicolumn{8}{|c|}{ Populations } \\
\hline Symptoms & Adults (\%) & $\mathrm{HCW}(\%)$ & Com children $(\%)$ & Children heart (\%) & Renal TPL (\%) & $\operatorname{SCTP}(\%)$ & Hospitalized (\%) \\
\hline Fever & 83.3 & 72.7 & 81.8 & 50.0 & 23.3 & 41.4 & 100.0 \\
\hline Cough & 83.3 & 81.8 & 100.0 & 90.0 & 71.4 & 72.0 & 100.0 \\
\hline Wheezing & - & - & 27.2 & 25.0 & - & 0 & 25.0 \\
\hline Cyanosis & - & - & 0 & 5.0 & - & 0 & 0 \\
\hline Dyspnea & - & - & 27.2 & 25.0 & - & 30.0 & 50.0 \\
\hline Coryza & 100.0 & 90.9 & 100.0 & 90.0 & 86.6 & 81.3 & 25.0 \\
\hline Sore throat & 33.3 & 81.8 & 0 & 0 & 28.5 & 15.0 & 25.0 \\
\hline Headache & 100.0 & 100.0 & 0 & 0 & 46.4 & 18.9 & 25.0 \\
\hline Diarrhea & 0 & 0 & 0 & 0 & 0 & 2.6 & 25.0 \\
\hline
\end{tabular}

Note. HCW: healthcare workers; Renal TPL: renal transplanted patients; children heart: children with heart diseases; SCTP: patients under stem cell transplantation program; com children: children from community; hospitalized: hospitalized patients.

Healthcare workers presented more sore throat and myalgia than the other studied populations.

\section{Discussion}

Viral respiratory diseases are the leading cause of medical attendance worldwide exerting a great economic impact on the health-care system. Human coronavirus is considered one of the most common respiratory viruses associated with respiratory tract infections, mainly among children. Epidemiological and clinical data of HCoVs infectious in the Brazilian population are scarce and restricted to one or two group of patients. Bellei et al. (2008) reported $4.2 \%$ of human coronaviruses in Brazilian adults, Cabeça and Bellei (2012) described a fatal case of HCoVNL63 associated with pneumonia in a Brazilian adult and Albuquerque et al. (2009) reported 1.9\% among Brazilian children. This is the first Brazilian report of $\mathrm{HCoVs}$ from distinct Brazilian population over a period of nine years.

Detection of coronaviruses by culture isolation or serological methods is difficult. A pancoronavirus RT-PCR assay is a usefull molecular tool to test for all coronaviruses in a clinical sample. In addition, quick screening for several pathogens in one assay allows the identification of previously unknown coronaviruses. However, the pancoronavirus RT-PCR assay used could have led to some limitations in our study. First, HCoVs subtypes were not identified and the prevalence of our study could be overestimated and/or underestimated once the assay included non specific primers that target all human and animal coronaviruses. Therefore, the use of degenerate primers set in a conventional RT-PCR may enhance detection of coronavirus genome variations, but may also miss samples with less genome copies. To have a better understanding about it and mainly to rule out the possibility of a bias, we sequenced a portion of the coronaviruses positive cases detected in the present study using pancoronavirus primers set. The positive cases detected among hospitalized patients from 2009 to 2010 were sequenced and all samples were confirmed as human coronaviruses (Cabeça et al., 2012).

Coronaviruses can display a typical biennial seasonality different than occur with other respiratory viruses (McIntosh et al., 1970; Monto et al., 1974; Vabret et al., 2003). In this regard, we identified peaks of detection frequency of HCoVs during 2002-2004 and 2008-2009, with high detection frequencies in winter months but few or no detections in the summer.

The prevalence of $11.5 \%$ found in our study corroborated with other research that identified coronaviruses as responsible for $10-30 \%$ of common colds and $0.3-9 \%$ associated with pneumonia (Tyrrell and Bynoe, 1965; Bradburne and Somerset, 1972; Larson et al., 1980; Dare et al., 2007). We demonstrate the presence of HCoVs infection in all studied populations, with a significant prevalence among some at-risk group patients, such as patients under stem cell transplantation program and children with heart diseases. This higher frequency of HCoVs may be related to the functional condition of these patients. On the other hand, a lower prevalence was observed among children from community when compared with our different studied populations. Since the majority of these children presented influenza-like illness instead of common cold symptoms, the clinical pattern can explain this lower frequency among this group of patients. Underlying conditions other than cardiac/transplantation were observed among $20 \%$ of coronaviruses-infected patients. This data along with the higher prevalence of coronaviruses-infected cases found in specific at-risk group patients pointed to the relevance of coronaviruses causing respiratory tract illness in patients with comorbidities.

In conclusion, our results provided a novel insight into the epidemiology and clinical knowledge of coronaviruses in different groups of the Brazilian population, sup- 
porting the notation that $\mathrm{HCoV}$ may have an important role among patients with underlying conditions and transplanted ones.

\section{Acknowledgments}

We would like to thank Dr. Luis Vicente Ribeiro Ferreira da Silva Filho for providing us the Human coronavirus control for assay validation. This project was supported by Fundação de Amparo à Pesquisa do Estado de Sao Paulo, Brazil (FAPESP) (n09/17307-6).

\section{References}

Albuquerque MCM, Pena GPA, Varella RB, Gallucci G, Erdman DD, Santos N (2009) Novel Respiratory Virus Infections in Children, Brazil. Emerg Infect Dis 15:806-808.

Bellei N, Carraro E, Perosa A, Watanabe AS, Arruda E, Granato C (2008) Acute Respiratory Infection and Influenza-Like Illness Viral Etiologies in Brazilian Adults. J Med Virol 80:1824-1827.

Bradburne AF, Somerset BA (1972) Coronative antibody tires in sera of healthy adults and experimentally infected volunteers. J Hyg 70: 235-44.

Chiu SS, Chan KH, Chu KW, Kwan SW, Guan Y, Poon LL, Peiris JS (2005) Human coronavirus NL63 infection and other coronavirus infections in children hospitalized with acute respiratory disease in Hong Kong, China Clin Infect Dis 40:1721-1729.

Dare RK, Fry AM,Chittaganpitch M,Sawanpanyalert P, Olsen SJ, Erdman DD (2007) Human Coronavirus Infections in Rural Thailand: A Comprehensive Study Using Real-Time Reverse-Transcription Polymerase Chain Reaction Assays. J Infect Dis 196: 1321-1328.

Drosten C, Gunther S, Preiser W, van der Werf S, Brodt HR, Becker S, Rabenau H, Panning M, Kolesnikova L, Fouchier RA, Berger A, Burguiere AM, Cinatl J, Eickmann M, Escriou N, Grywna K, Kramme S, Manuguerra JC, Muller S, Rickerts V, Sturmer M, Vieth S, Klenk HD, Osterhaus AD, Schmitz H, Doerr HW (2003) Identification of a novel coronavirus in patients with severe acute respiratory syndrome. N Engl J Med 348:1967-1976.

Gerna G, Percivalle E, Sarasini A, Campanini G, Piralla A, Rovida F, Genini E, Marchi A, Baldanti F (2007) Human respiratory coronavirus HKU1 vs. other coronavirus infections in Italian hospitalised patients. J Clin Virol 38:244-250.

Hamre D, Procknow JJ (1966) A new virus isolated from the human respiratory tract. Proc Soc Exp Biol Med 121:190-193.

Hendley JO, Fishburne HB, Gwaltney JM (1972) Coronavirus infections in working adults. Eight-year study with $229 \mathrm{E}$ and OC43. Am Rev Respir Dis 105: 805-811.
Larson HE, Reed SE, Tyrell DAJ (1980) Isolation of rhinoviruses and coronaviruses from 38 colds in adults. J Med Virol 5:221-229.

McIntosh K, Kapikian AZ, Turner HC, Hartley JW, Parrott RH, Chanock RM (1970) Seroepidemiologic studies of coronavirus infection in adults and children. Am J Epidemiol 91:585-92.

Monto AS, Lim SK (1974) The Tecumseh study of respiratory illness. VI. Frequency of and relationship between outbreaks of coronavirus infection. J Infect Dis 129:271-276.

Murray RS, Brown B, Brian D, Cabirac GF (1992) Detection of coronavirus RNA and antigen in multiple sclerosis brain. Ann Neurol 31:525-533.

Resta S, Luby JP, Rosenfeld CR, Siegel JD (1985) Isolation and propagation of human enteric coronavirus. Science 229:978-981.

Stewart JN, Mounir S, Talbot PJ (1992) Human coronavirus gene expression in the brains of multiple sclerosis patients. Virology 191:502-505.

Tyrrell DA, Bynoe ML (1965) Cultivation of a novel type of common-cold virus in organ cultures. Br Me J 1:1467-1470.

Vabret A, Mourez T, Gouarin S, Petitjean J, Freymuth F (2003) An Outbreak of Coronavirus OC43 Respiratory Infection in Normandy, France. Clin Infect Dis 36:985-9.

van Elden LJ, van Loon AM, van Alphen F, Hendriksen KA, Hoepelman AI, van Kraaij MG, Oosterheert JJ, Schipper P, Schuurman R, Nijhuis M (2004) Frequent detection of human coronaviruses in clinical specimens from patients with respiratory tract infection by use of a novel real-time reverse-transcriptase polymerase chain reaction. J Infect Dis 189:652-657.

van der Hoek L, Pyrc K, Jebbink MF, Vermeulen-Oost W, Berkhout RJ, Wolthers KC, Wertheim-van Dillen PM, Kaandorp J, Spaargaren J, Berkhout B (2004) Identification of a new human coronavirus. Nat Med 10:368-373.

Vijgen L, Moës E, Keyaerts E, Li S, van Ranst M (2008) A Pancoronavirus RT-PCR Assay for Detection of All Known Coronaviruses. Methods Mol Biol 454:3-12.

Woo PC, Lau SK, Chu CM, Chan KH, Tsoi HW, Huang Y, Wong BH, Poon RW, Cai JJ, Luk WK, Poon LL, Wong SS, Guan Y, Peiris JS, Yuen KY (2005) Characterization and complete genome sequence of a novel coronavirus, coronavirus HKU1, from patients with pneumonia. J Virol 79:884-895.

Cabeça TK, Bellei N (2012) Human coronavirus NL-63 infection in a Brazilian patient suspected of H1N1 2009 influenza infection: Description of a fatal case. J Clin Virol 53:82-84. Epub 2011 Oct 5.

Cabeça TK, Carraro E, Watanabe A, Granato C, Bellei N (2012) Infections with human coronaviruses NL63 and OC43 among hospitalised and outpatient individuals in São Paulo, Brazil. Mem Inst Oswaldo Cruz 107:693-694.

All the content of the journal, except where otherwise noted, is licensed under a Creative Commons License CC BY-NC. 